\title{
Induction of apoptosis by capsaicin in hepatocellular cancer cell line SMMC-7721 is mediated through ROS generation and activation of JNK and p38 MAPK pathways
}

\author{
H. Q. BU, K. CAI ${ }^{\ddagger}$, F. SHEN ${ }^{\ddagger}$, X. D. BAO, Y. XU, F. YU, H. Q. PAN, C. H. CHEN, Z. J. DU, J. H. CUI* \\ Department of Coloproctological Surgery, Tongde Hospital of Zhejiang Province, Hangzhou, P.R. China \\ ${ }^{*}$ Correspondence to: $13958105761 @ 163 . c o m$ \\ ${ }^{*}$ Contributed equally to this work.
}

Received September 2, 2014 / Accepted February 18, 2015

\begin{abstract}
Capsaicin, one of the major pungent ingredients found in red peppers, has been shown to have anti-carcinogenic effect on various cancer cells through multiple mechanisms. In this study, we investigated the apoptotic effect of capsaicin on human hepatocellular cancer cell line SMMC-7721, as well as the possible mechanisms involved. Treatment of SMMC-7721 cells with capsaicin resulted in a dose-dependent inhibition of cell-viability and induction of apoptosis which was associated with the generation of ROS and persistent disruption of mitochondrial membrane potential. These effects were significantly blocked when cells were pretreated with a general antioxidant $\mathrm{N}$-acetyl cysteine (NAC). We also found that capsaicin induced JNK and p38 MAPK phosphorylation. JNK and p38 MAPK inhibitor effectively blocked capsaicin-induced SMMC-7721 cell apoptosis. In addition, NAC completely blocked phosphorylation of JNK and p38 MAPK induced by capsaicin. Our results indicate that capsaicin induced in SMMC-7721 cell apoptosis through generation of intracellular ROS and activation of JNK and p38 MAPK pathways.
\end{abstract}

Key words: capsaicin, hepatocellular cancer, apoptosis, ROS, JNK and p38

Hepatocellular carcinoma is the sixth most common solid cancer and the third leading cause of cancer-related mortality worldwide [1]. The occurrence of hepatocellular carcinoma is multi-factorial and it often develops under an established background of chronic liver diseases [2, 3]. In 2008, there were estimated 748,300 new liver cancer cases and 695,900 cancer mortalities worldwide [4,5]. Half of these cancer cases and cancer-associated mortalities were estimated to occur in China [6]. Liver transplantation or surgical resection remain the first-line treatments for hepatocellular carcinoma [7]. However, patients often present symptoms at the advanced stages of hepatocellular carcinoma and, therefore, the first-line treatments are not effective for the majority of Hepatocellular carcinoma cases. Due to high recurrence rates, even following surgical resection, the long-term prognosis of hepatocellular carcinoma remains unsatisfactory. Chemotherapy is often the only treatment for advanced and inoperable hepatocellular carcinoma. However, its outcomes are often discouraging due to poor tolerance and low efficacy [8]. It is therefore of particular interest to impose new therapeutic strategies and to improve the prognosis of this potentially fatal disease.

It is reported that herbal and botanical products, as well as selected food supplements and spices have an anticarcinogenic potential [9]. Capsaicin (N-vanillyl-8-methyl-1-nonenamide) is a homovanillic acid derivative and the chief pungent principle found in hot red chilli peppers derived from Capsicum fruit extracts [10]. Due to its analgetic activity, topical application of capsaicin has been used in clinical practice for the treatment of neuropathic pain [11]. Capsaicin has been revealed to inhibit growth and induce apoptosis in various malignant cell lines [12-18]. The mechanisms included generation of reactive oxygen species, disruption of mitochondrial transmembrane potential, and activation of caspase- 9 and caspase-3. Recently, reports have shown that capsaicin triggers apoptosis in human hepatoma HepG2 cells [19, 20]. However, the mechanisms underlying capsaicin-induced apoptosis are still not well established.

In the present study, we investigated whether capsaicin could induce apoptosis in human hepatoma cancer SMMC- 
7721 cells, and determined the effect of intracellular ROS and JNK, p38 MAPK on capsaicin-induced SMMC-7721 cell apoptosis. We showed for the first time that capsaicin induced intracellular ROS generation and activated JNK and p38 MAPK, which contributed to SMMC-7721 cell apoptosis. Taken together, the present study provides strong evidence supporting an important role of ROS and JNK, p38 MAPK in mediating capsaicin-induced apoptosis in hepatoma cancer cells.

\section{Materials and methods}

Chemicals and reagents. Capsaicin (purity $>99 \%$ ), Ribonuclease A (RNase A), DCFH-DA, DiOC 6 , N-acetylcysteine(NAC) and dimethyl sulfoxide (DMSO) were obtained from SigmaAldrich (St. Louis, MO, USA). Fetal bovine serum (FBS), trypsin containing EDTA, Roswell Park Memorial Institute1640 (RPMI-1640) and the Cell Counting Kit-8 (CCK-8) were obtained from Gibco BRL (Invitrogen, Grand Island, NY, USA). Annexin V-FITC/PI Apoptosis Detection Kit I was obtained from BD Bioscience. p38 inhibitor SB203580 and JNK inhibitor SP600125 were obtained from Calbiochem (San Diego, CA, USA). Antibodies against JNK, p38, phosphoJNK (Thr183/Tyr185), and phospho-p38 (Thr180/Tyr182), cytochrome $c$, caspase-3, $\beta$-actin and horseradish peroxidase (HRP)-conjugated secondary antibodies (goat anti-rabbit and goat anti-mouse) were purchased from Sigma.

Cell line and cell culture. The human hepatoma cancer SMMC-7721 cell line and normal hepatic cell line L-02 were obtained from the American Type Culture Collection. All cells were cultured in RPMI-1640 medium supplemented with 10\% FBS, 100 units/mL penicillin, and $100 \mu \mathrm{g} / \mathrm{mL}$ streptomycin. Cells were maintained at $37^{\circ} \mathrm{C}$ in a humidified atmosphere of $5 \% \mathrm{CO}_{2}$. The medium was changed every $2 \sim 3$ days, and cells were subcultured when confluency reached $70 \% \sim 80 \%$ by $0.25 \%$ trypsin at $37^{\circ} \mathrm{C}$.

Cell viability assay. Cell viability was determined using the Cell Counting Kit-8 (CCK-8) assay. Briefly, The logarithmic phase human hepatoma cancer SMMC-7721 cells and normal L-02 cells were plated in 96 -well culture plates $\left(5 \times 10^{3}\right.$ cells per well). After $24 \mathrm{~h}$ incubation, the cells were treated with vehicle alone $(0.1 \% \mathrm{DMSO})$ at various concentrations $(50,100,150$, 200,250 and $300 \mu \mathrm{M}$ ) of capsaicin, followed by $48 \mathrm{~h}$ cell culture. Each group had 6 wells. $100 \mu \mathrm{L}$ CCK- 8 was added to each well 1 $\mathrm{h}$ before the end of incubation. The absorbance (A) of each well was read at $450 \mathrm{~nm}$ using an enzyme-linked immunosorbant assay (ELISA) reader (Bio-Tek ELx808, Winooski, VT, USA). Experiment was repeated three times. Percentage suvival rate was calculated using the following equation: Survival rate (\%) $=\left(\mathrm{A}_{\text {sample }}-\mathrm{A}_{\text {blank }}\right) /\left(\mathrm{A}_{\text {control }}-\mathrm{A}_{\text {blank }}\right) \times 100 \%$.

Apoptosis assay. Apoptosis assay was performed using Annexin V-FITC kit as described in the manufacturer's instructions. SMMC-7721 cells were cultured in medium containing different concentrations of capsaicin $(0,150,200$ or $250 \mu \mathrm{M})$ for $48 \mathrm{~h}$ at 6 -well plates, and the floating and adherent cells were collected by centrifugation at $1000 \times \mathrm{g}$ for $5 \mathrm{~min}$. Pooled cells were washed twice with cold PBS, gently resuspended in $100 \mu \mathrm{l}$ of annexinV-FITC binding buffer. Then, $5 \mu \mathrm{l}$ Annexin V-FITC and $10 \mu \mathrm{l}$ PI were added and incubated with the cells for $15 \mathrm{~min}$ in the dark at room temperature. The stained cells were analyzed directly by flow cytometry using the Cell Quest program (Becton-Dickinson).

Caspase-3 activity assay. Caspase- 3 activities were assayed using a Colorimetric Protease Assay Kit according to the manufacturer's instructions (Keygen Biotech, Nanjing, China). Briefly, SMMC-7721 cells were treated with different concentrations of capsaicin $(0,150,200$ or $250 \mu \mathrm{M})$ for $48 \mathrm{~h}$. The cells $\left(1 \times 10^{6}\right.$ cells $\left./ \mathrm{mL}\right)$ were harvested, washed three times with PBS and re-suspended in $50 \mu \mathrm{l}$ of the lysis buffer, kept on ice for $60 \mathrm{~min}$, and then centrifuged $(10,000 \mathrm{x} \mathrm{g}, 1 \mathrm{~min}$ at $4^{\circ} \mathrm{C}$ ). Supernatants containing $100 \mu \mathrm{g}$ of protein were incubated with $5 \mu$ l of enzyme specific colorimetric substrates Ac-DEVD-pNA $(2 \mathrm{mM})$, at $37^{\circ} \mathrm{C}$ for $4 \mathrm{~h}$. The colorimetric release of p-nitroaniline from the Ac-DEVD-pNA substrate was measured using a lightwave of $405 \mathrm{~nm}$ with an ELISA reader (BIO-Tek ELx800).

Measurement of intracellular ROS. Intracellular ROS generation was determined by measuring the levels of super-oxide and hydrogen peroxide produced in the cells by flow cytometry after staining with 6-carboxy-2, 7-dichlorodihydrofluorescein diacetate (DCFH-DA) as described previously [21]. Fluorescence generation was due to the hydrolysis of DCFH-DA to dichlorodihydrofluorescein (DCFH) by non-specific cellular esterases, and the subsequent oxidation of DCFH by peroxides was measured by means of flow cytometry. Briefly, SMMC7721 cells $\left(1 \times 10^{6}\right.$ cells/well $)$ were seeded in 6 -well plates for $24 \mathrm{~h}$ and then exposed to different concentrations $(0,150$, 200 or $250 \mu \mathrm{M}$ ) of capsaicin. After incubation for $48 \mathrm{~h}$, cells were harvested and washed twice, re-suspended in $500 \mu \mathrm{l}$ of DCFH-DA $(10 \mu \mathrm{M})$ incubated at $37^{\circ} \mathrm{C}$ in the dark for $30 \mathrm{~min}$ and analyzed by flow cytometry (Becton Dickinson FACS Calibur). Approximately 10,000 cells were evaluated for each sample. The data are means from experiments performed in triplicate.

The changes of mitochondrial membrane potential (MMP). The level of Mitochondrial Membrane Potential in SMMC-7721 cells was determined by flow cytometry (Becton Dickinson FACS Calibur) using $\mathrm{DiOC}_{6}(4 \mu \mathrm{mol} / \mathrm{l})$. Briefly, SMMC-7721 cells $\left(1 \times 10^{6}\right.$ cells/well $)$ were seeded in a 6-well plate. After adherence for $24 \mathrm{~h}$, cells were treated with different concentrations $(0,150,200$ or $250 \mu \mathrm{M})$ of capsaicin. After incubation for $48 \mathrm{~h}$, The cells were harvested and washed twice, re-suspended in $500 \mu \mathrm{l}$ of DiOC6 $(4 \mu \mathrm{mol} / \mathrm{L})$ and incubated at $37^{\circ} \mathrm{C}$ for $30 \mathrm{~min}$, followed by immediate analysis by flow cytometry at $488 \mathrm{~nm}$.

Western blot analysis. SMMC-7721 cells were exposed to the desired concentration of capsaicin in the absence or presence of inhibitors for the indicated periods. Both adherent and floating cells were collected, and then western blot analysis was performed. The cells were washed with ice-cold 
PBS, and lysed on ice for $40 \mathrm{~min}$ in a solution containing $50 \mathrm{mM}$ Tris, $1 \%$ Triton X-100, 0.1\% SDS, $150 \mathrm{mM} \mathrm{NaCl}$, $2 \mathrm{mM}$ Na3VO4, 2 mM EGTA, $12 \mathrm{mM} \beta$-glycerolphosphate, $10 \mathrm{mM} \mathrm{NaF}, 16 \mu \mathrm{g} / \mathrm{ml}$ benzamidine hydrochloride, $10 \mu \mathrm{g} /$ $\mathrm{ml}$ phenanthroline, $10 \mu \mathrm{g} / \mathrm{ml}$ aprotinin, $10 \mu \mathrm{g} / \mathrm{ml}$ leupeptin, $10 \mu \mathrm{g} / \mathrm{ml}$ pepstatin, and $1 \mathrm{mM}$ phenylmethylsulfonyl fluoride, and then lysed at $4^{\circ} \mathrm{C}$ for $60 \mathrm{~min}$. The cell lysate was centrifuged at $14,000 \times \mathrm{g}$ for $15 \mathrm{~min}$, and the supernatant fraction was collected for western blotting. Protein content in the supernatant fraction was determined by bicinchoninic acid (BCA) assay kit (Sigma) according to the manufacturer's instructions. The protein lysates $(20 \mu \mathrm{g} /$ lane $)$ were separated by electrophoresis on $12 \%$ SDS polyacrylamide gel and then transferred to a nitrocellulose membrane. After blocking for $1 \mathrm{~h}$ in $10 \%$ nonfat dry milk in Tris-buffered saline, the membrane was incubated with the desired primary antibody for $1 \mathrm{~h}$. The membrane was then treated with the appropriate peroxidase-conjugated secondary antibody, and the immunoreactive proteins were detected using an enhanced chemiluminescence kit (NEN Life Science Products, Boston, MA, USA) according to the manufacturer's instructions. Each membrane was stripped and reprobed with antibodies against actin to correct for differences in protein loading. Quantitative data were expressed as mean \pm SD of the relative levels of the objective protein and control $\beta$-actin of each group of cells from three independent experiments.

Statistical analysis. All results were confirmed in at least three separate experiments. Statistical analysis was performed using SPSS 17.0. Significant differences were determined by ANOVA, followed by the Student's t-test for statistical analysis. The data were expressed as mean \pm SD. A P-value $<0.05$ was considered to indicate a statistically significant difference.

\section{Results}

Drug toxicity test. To investigate the effect of capsaicin on growth, SMMC-7721 and L-02 cells were treated with increasing concentrations of capsaicin $(0-300 \mu \mathrm{M})$ for $48 \mathrm{~h}$. Cell viability was determined by CCK-8 assay. As shown in Fig. 1, the growth of SMMC-7721 cells was significantly inhibited by capsaicin treatment in a dose-dependent manner with an $\mathrm{IC}_{50}$ of about $200 \mu \mathrm{M}$. On the other hand, the viability of normal hepatic cells was minimally affected following exposure even to high concentrations of capsaicin that were highly cytotoxic to cancer cells

Effects of capsaicin on induction of apoptosis. To determine whether the antiproliferative activity of capsaicin in SMMC-7721 cells was caused by apoptosis. SMMC-7721 cells were treated with varying concentrations of capsaicin $(0,150$, 200 or $250 \mu \mathrm{M}$ ) for $48 \mathrm{~h}$, and flow cytometric analysis was performed using Annexin V-FITC/PI-stained SMMC-7721 cells. We found that the apoptotic cell ratio in the control group was $\sim 8.5 \pm 0.8 \%$, while the numbers of apoptotic cells in the presence of capsaicin-treated groups increased to $20.9 \pm 1.2 \%, 40.6 \pm 1.7 \%$ and $52.1 \pm 1.9 \%$ at $48 \mathrm{~h}$, respectively. There were significant differences in the apoptotic ratio of cells between the capsaicin-treated groups and the control group $(\mathrm{P}<0.05)$ (Fig. 2A and B). To further examine the ability of the capsaicin therapy to induce apoptosis, caspase-3 activities in SMMC-7721 cells were evaluated. As demonstrated in Fig. $2 \mathrm{C}$, a dose-dependent increase in the caspase- 3 activity was observed after the exposure of cells to increasing concentrations of capsaicin. Next, we evaluated caspase-3 activation in SMMC-7721 cells tested by Western blotting. The capsaicin treatments also induced a dose-dependent activation of caspase-3 in SMMC-7721 cells (Fig. 2D and E).

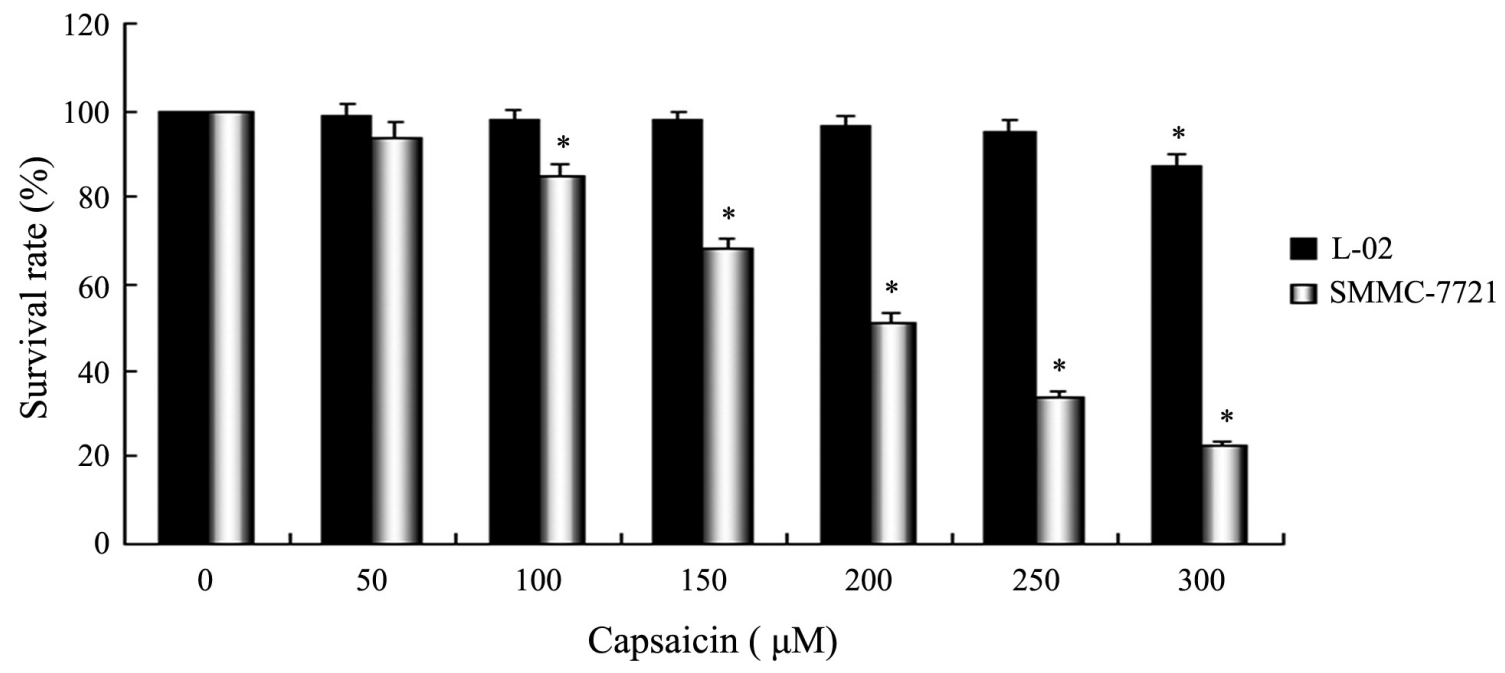

Figure 1. Toxicity effects of capsaicin on SMMC-7721 and L-02 cells as determined by Cell Counting Kit-8 (CCK-8) assay. The SMMC-7721 and L-02 cells were treated with different concentrations of capsaicin for $48 \mathrm{~h}$. cell viability was measured using CCK-8 assay with six replicates per concentration of capsaicin. Results of data derived from three separate experiments are expressed as percent survival of capsaicin treated cells compared to that of DMSO treated control cells. data are presented as mean $\pm \mathrm{SD}$. ${ }^{\star} \mathrm{P}<0.05$ vs. the control. 
Capsaicin causes ROS generation and disrupts the mitochondrial membrane potential ( MMP) in SMMC-7721 cells. The disruption of mitochondrial integrity is one of the early events leading to apoptosis. Loss of MMP is an important event during the mitochondrial pathway of apoptosis [22]. Several studies have implicated reactive oxygen species (ROS) generation as a possible mechanism for induction of apoptosis by various anticancer agents [23]. And a loss of MMP is associated with the generation of ROS. We wanted to determine whether capsaicin induced the loss of MMP and the generation of ROS in SMMC-7721 cells. Therefore, intracellular ROS generation the changes of MMP in control and capsaicin-treated
A

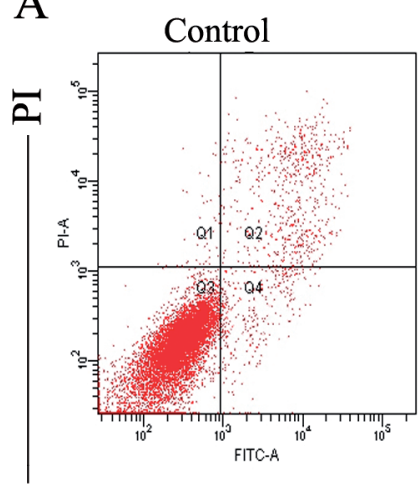

B

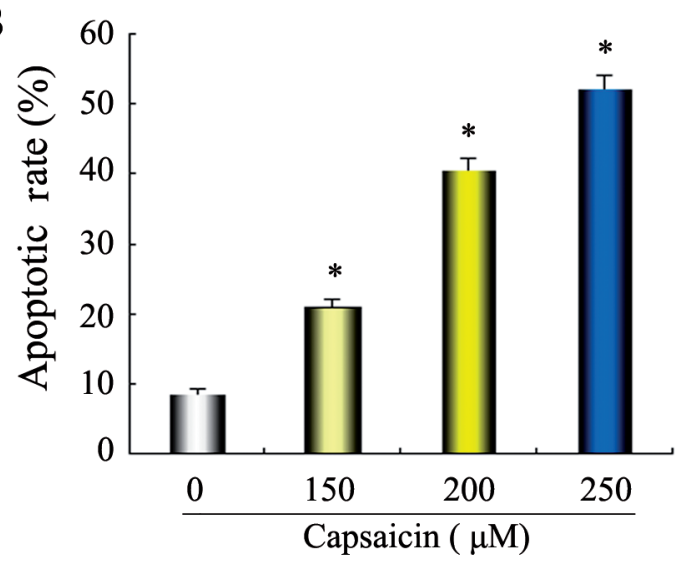

$\mathrm{D}$
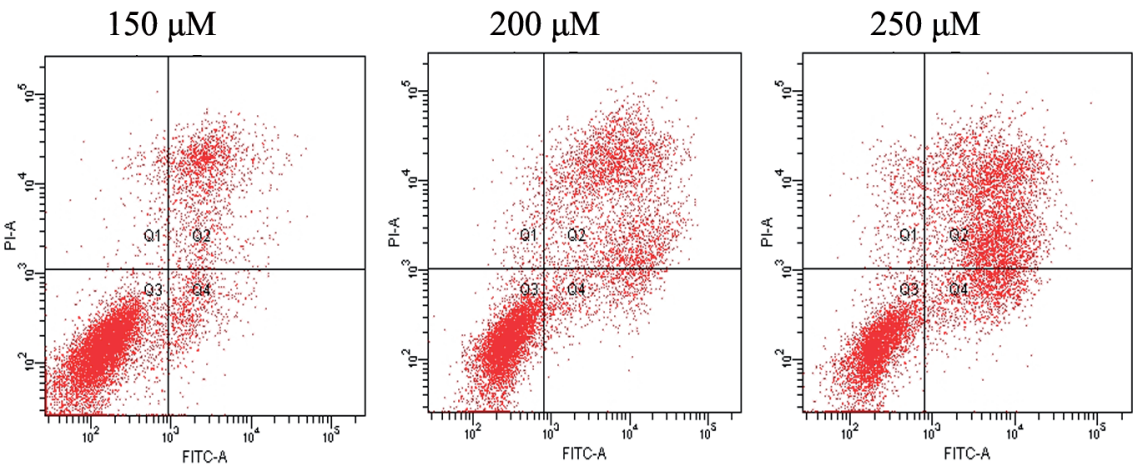

Annexin V

$\mathrm{C}$

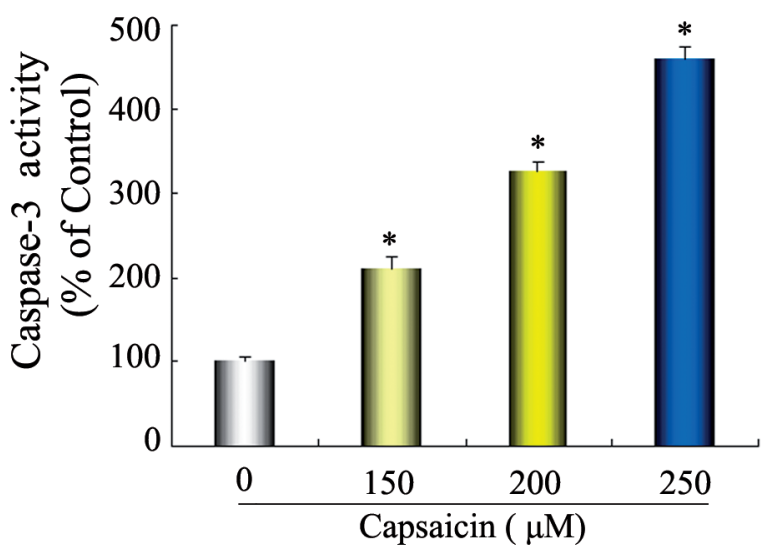

$\mathrm{E}$

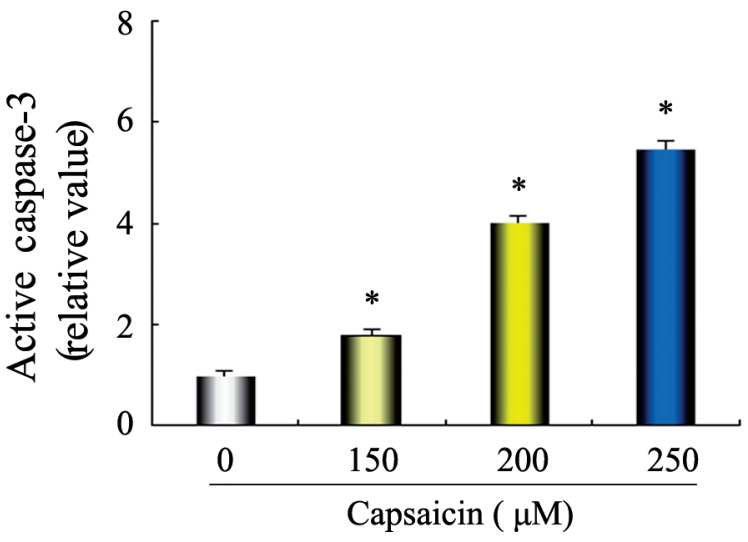

Figure 2. Apoptosis-inducing effects of capsaicin in SMMC-7721 cells. (A) The SMMC-7721 cells were treated with various concentrations of capsaicin $(150,200,250 \mu \mathrm{M})$ or vehicle for $48 \mathrm{~h}$, and then stained with Annexin V-FITC/PI and analyzed by flow cytometry. Results were representative of three independent experiments. (B) The percentage of apoptotic cells was presented as the mean $\pm \mathrm{SD}$ of three independent experiments. ${ }^{\star} \mathrm{P}<0.05 \mathrm{vs}$. the control. (C) Cell lysates were assayed for caspase-3 activity as described in Materials and methods. Data were presented as the mean \pm SD of three independent experiments. ${ }^{\star} \mathrm{P}<0.05$ vs. the control. (D) Active caspase- 3 protein levels were investigated by Western blot. $\beta$-actin protein was performed as loading control. (E) Quantified data of Western blot analysis were presented. ${ }^{\star} \mathbf{P}<0.05$ vs. the control. 


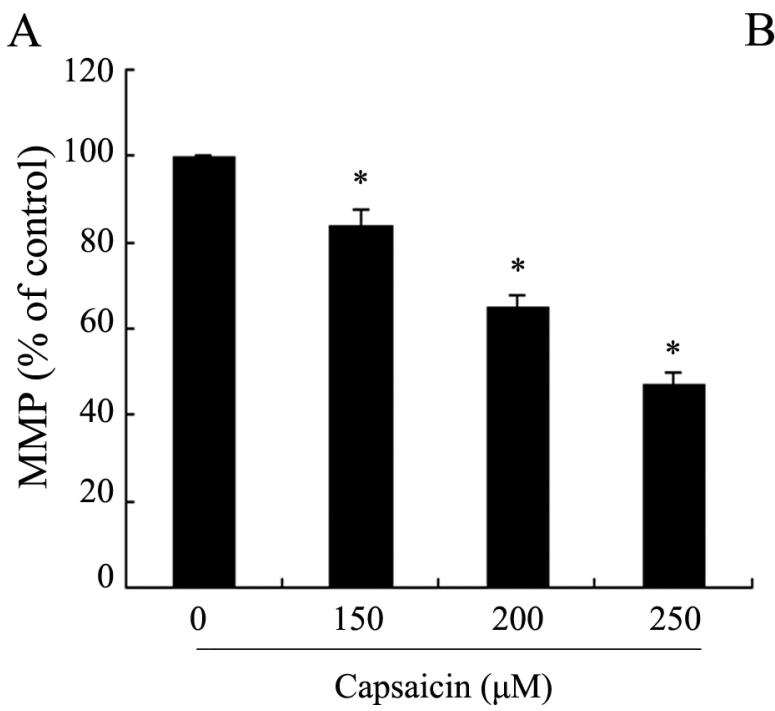

B

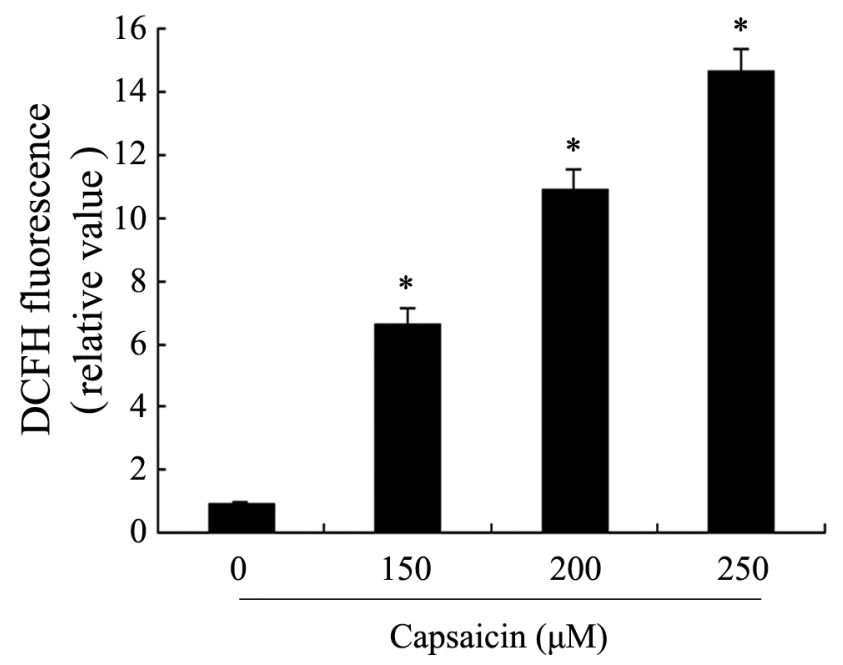

Figure 3. Effects of capsaicin on MMP and Intracellular ROS in SMMC-7721 cells. SMMC-7721 cells were treated with various concentrations of capsaicin $(150,200,250 \mu \mathrm{M})$ or vehicle for $48 \mathrm{~h}$. The zero concentration was defined as control and all other variables expressed relative to it. ROS and MMP were determined by staining with DCFH-DA and $\mathrm{DiOC}_{6}$, respectively. The stained cells were determined by flow cytometry as described in the Materials and Methods. (A) the changes of cells being stained for MMP were presented. (B) the changes of cells being stained for ROS were presented. Results are expressed as the mean \pm SD $(n=3)$ from three independent experiments. ${ }^{\star} \mathrm{P}<0.05$ vs. the control.

cells were evaluated by flow cytometry. As shown in Fig. 3, As compared with the control group, the MMP decreased to 84.35 $\pm 3.04 \%, 65.17 \pm 2.78 \%$ and $47.48 \pm 2.39 \%$ in cells treated with capsaicin at 150, 200 and $250 \mu \mathrm{M}$, respectively. While the level of DCFH fluorescence(ROS generation) increased to $6.71 \pm$ $0.45 \%, 10.93 \pm 0.62 \%$ and $14.68 \pm 0.71 \%$ in cells treated with capsaicin at 150,200 and $250 \mu \mathrm{M}$, respectively. These results demonstrated that capsaicin induced mitochondria damage, diminished MMP and increased ROS production in SMMC7721 cells in a concentration-dependent manner. Studies have confirmed that high intracellular ROS normally disrupted the mitochondrial membrane potential. so we reasoned that ROS production might promote mitochondrial dysfunction and trigger mitochondria-mediated apoptosis.

Capsaicin-induced ROS generation triggers apoptosis in SMMC-7721 cells. Next we sought to determine whether generation of ROS was an upstream event of capsaicin -mediated mitochondrial membrane damage and induction of apoptosis. When pretreatment of SMMC-7721 cells with $5 \mathrm{mM}$ NAC (a general antioxidant) for $1 \mathrm{~h}$, Our results revealed that capsaicin-mediated increase in ROS levels was significantly reduced and capsaicin-mediated decrease in mitochondrial membrane potential was considerably prevented (Fig. 4A), release of cytochrome $c$ in the cytosol (Fig. 4B) and apoptosis induction in SMMC-7721 cells (Fig. 4A) were also obviously blocked. These results clearly established the protective role of NAC and involvement of ROS in capsaicin-mediated mitochondrial damage and cell apoptosis.

Capsaicin causes activation of JNK and p38 in SMMC7721 cells. Oxidant stress is known to activate MAPKs family, specifically JNK and p38, by phosphorylation [24]. Since capsaicin induced intracellular ROS generation, we speculated that JNK and p38 could be involved in capsaicin -induced apoptosis. Thus, we investigated whether capsaicin could induce JNK and p38 phosphorylation in SMMC-7721 cells. SMMC-7721 cells were treated with varying concentrations of capsaicin for $48 \mathrm{~h}$, followed by extraction of the cellular protein. The expressions of phosphorylated JNK and p38 were determined by Western blot analysis. As shown in Fig. 5 , capsaicin induced increase in the phosphorylation of JNK and p38 in a dose-dependent manner.

JNK and p38 mediated capsaicin-induced apoptosis in SMMC-7721 cells. To determine whether JNK and p38 were necessary for capsaicin-induced apoptosis, SMMC-7721 cells were treated in the absence or presence of JNK inhibitor (SP600125) or p38 inhibitor (SB203580) for $1 \mathrm{~h}$, respectively. capsaicin was subsequently added to the culture for $48 \mathrm{~h}$. Our results demonstrated that Apoptosis induction by capsaicin significantly attenuated upon treatment with inhibitors of JNK (SP600125) or p38 MAPK (SB203580) (Fig. 6A ). These results showed both JNK and p38 were associated for capsaicin-induced apoptosis in SMMC-7721 cells. To elucidate the mechanistic order of intracellular ROS production and JNK, p38 phosphorylation. SMMC-7721 cells were incubated with NAC, an ROS scavenger, prior to capsaicin treatment. phosphorylation of JNK and p38 in SMMC-7721 cells induced by capsaicin were almost blocked in the presence of NAC (Fig. 6B). These results suggested that intracellular ROS played a major role in the activation of JNK and p38 by capsaicin, as an upstream regulatory molecule in capsaicin-induced apoptosis in SMMC-7721 cells. 


\section{Discussion}

Epidemiologic studies have revealed that several dietary agents modulate diverse biochemical processes involved in carcinogenesis, including inhibition of carcinogen activation, cellular proliferation and tumor metastasis, blockade of tumor cell cycle progression and induction of apoptosis [25].
In vitro and in vivo studies have shown that dietary chemopreventive agents may serve as potent agents for enhancing the therapeutic effects of chemotherapy, radiotherapy or other standard therapeutics for the treatment of human cancers [26]. Capsaicin, a natural product from red chili pepper is the most frequently used spice all over the world, and has been demonstrated to possess inhibitory effects in various cancer
A
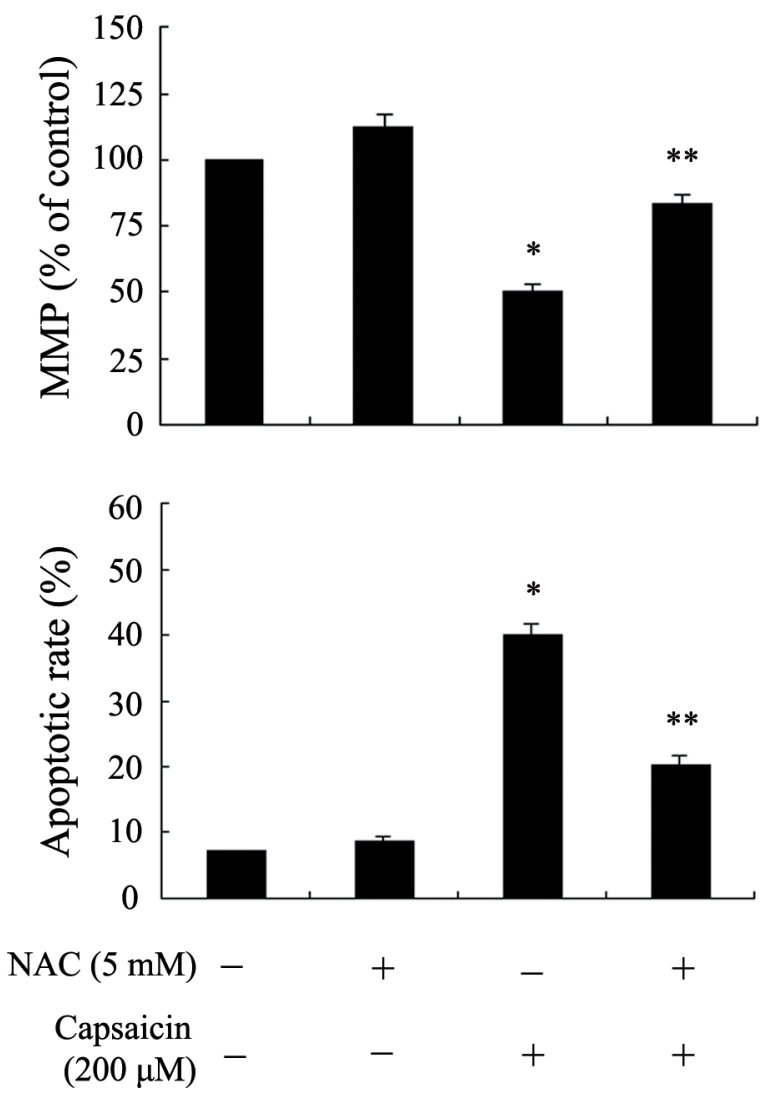

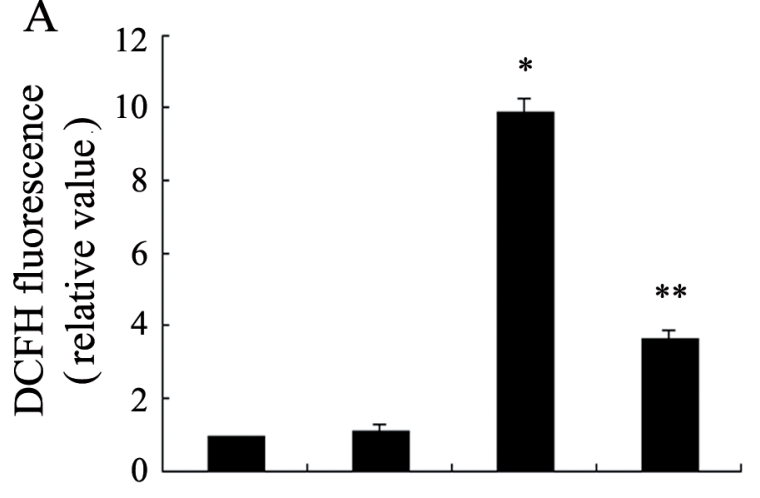

B

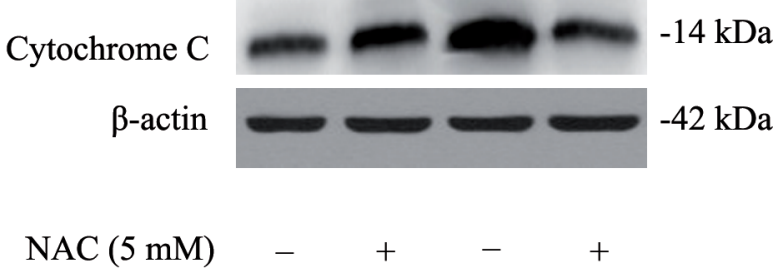

Capsaicin
$(200 \mu \mathrm{M})$

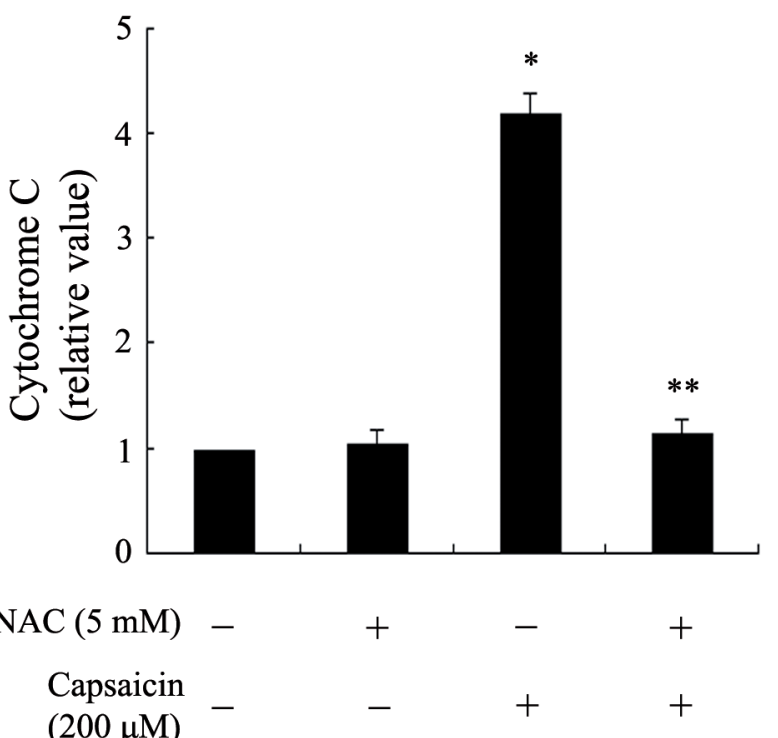

Figure 4. N-acetyl cysteine (NAC) pretreatment prevented capsaicin-mediated ROS generation, mitochondrial depolarization and apoptosis. (A) SMMC-7721 cells were pretreated with $5 \mathrm{mM} \mathrm{NAC}$ for $1 \mathrm{~h}$ and then treated with DMSO or $200 \mu \mathrm{M}$ capsaicin for $48 \mathrm{~h}$ and DCFH fluorescence, membrane potential and apoptosis were determined by flow cytometry. (B) Expression of cytochrome $\mathrm{c}$ was determined by Western blot and the quantification was performed assigning a value of 1 to the control group. the cytosolic fraction of the cells treated with NAC $(5 \mathrm{mM}, 1 \mathrm{~h})$ and/or capsaicin $(200 \mu \mathrm{M}, 48 \mathrm{~h})$. Each blot was stripped and reprobed with $\beta$-actin antibody to ensure equal protein loading. Results are expressed as the mean $\pm S D(n=3)$ from three independent experiments. ${ }^{\star} \mathrm{P}<0.05$ vs. the DMSO-treated control. ${ }^{*} \mathrm{P}<0.05$ vs. capsaicin treatment alone. 
cells. However, the precise molecular mechanisms have not been well elucidated in hepatoma cancer cells. In this study, we found that capsaicin significantly inhibited SMMC-7721 cells proliferation in a dose-dependent manner but was not toxic to normal hepatic cells, and this in vitro effect was through the induction of apoptosis. Furthermore, Capsaicin induced apoptosis in SMMC-7721 cells was associated with the genera- tion of ROS, disruption of mitochondrial membrane potential, release of cytochrome $\mathrm{c}$ in the cytosol which eventually led to the activation of caspase- 3 cascade. Interestingly, induction of apoptosis in SMMC-7721 cells was also mediated by the sustained activation of JNK and p38 which were reversed in the presence of NAC in capsaicin-induced SMMC-7721 cell apoptosis.
A

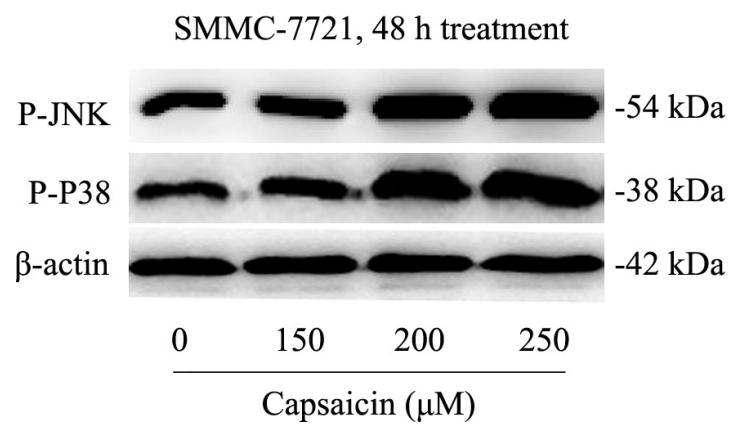

B

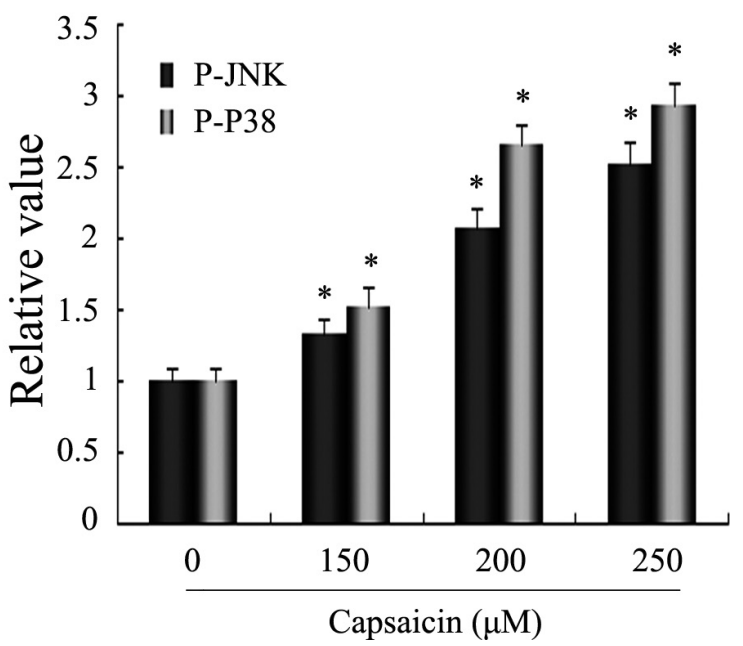

Figure 5. Capsaicin promoted the phosphorylation of JNK and p38 in SMMC-7721 cells. SMMC-7721 cells were treated with various concentrations of capsaicin $(150,200,250 \mu \mathrm{M})$ or vehicle for $48 \mathrm{~h}$. and phosphorylated JNK (P-JNK) and phosphorylated p38 (P-p38) protein expressions were detected by western blot analysis. (A) Treatment with capsaicin increased the expression of P-JNK and P-p38. (B) The relative levels of P-JNK and P-p38 in SMMC7721 cells. The quantification was performed assigning value 1 to the control group. ${ }^{\star} \mathrm{P}<0.05$ vs. the control.
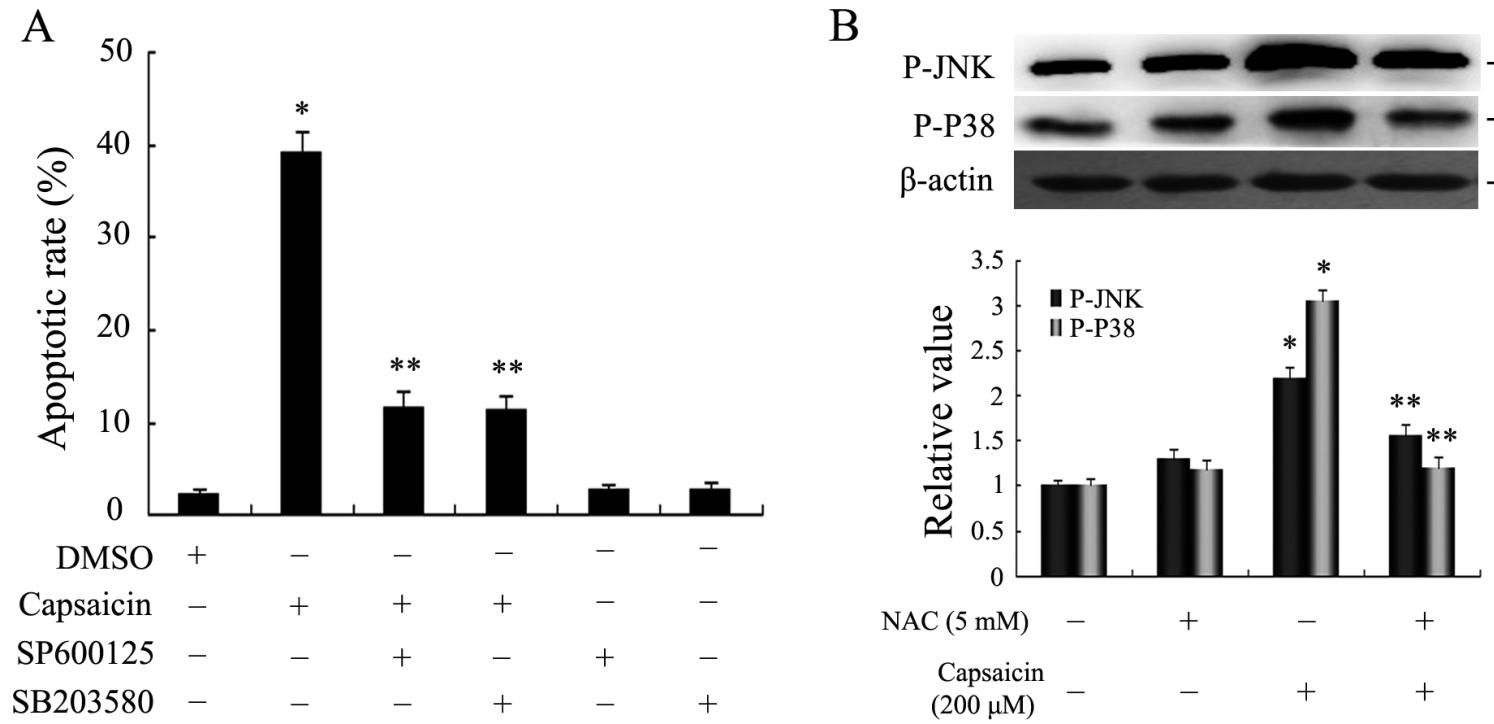

Figure 6. The role of JNK and p38 in capsaicin-induced apoptosis in SMMC-7721 cells. (A) Effects of JNK and p38 inhibitor on capsaicin-induced apoptosis. SMMC-7721 cells were pretreated with JNK inhibitor (SP600125, $20 \mu \mathrm{M})$ or p38 inhibitor (SB203580, $20 \mu \mathrm{M})$ for $1 \mathrm{~h}$ respectively. and then exposed to $200 \mu \mathrm{M}$ capsaicin for $48 \mathrm{~h}$ in the presence of inhibitor. Apoptosis was analyzed by flow cytometer. (B) Effects of NAC on JNK and p38 activation. Cells were treated with NAC ( $5 \mathrm{mM}, 1 \mathrm{~h})$ and/or capsaicin $(200 \mu \mathrm{M}, 48 \mathrm{~h})$. the phosphorylation of JNK and p38 was determined by Western blot. Each blot was stripped and reprobed with $\beta$-actin antibody to ensure equal protein loading. Data from three independent experiments were represented as mean $\pm \mathrm{SD}$. ${ }^{\star} \mathrm{P}<0.05$ vs. the DMSO-treated control. ${ }^{\star *} \mathrm{P}<0.05$ vs. capsaicin treatment alone. 
First, we investigated whether the antiproliferative activity of capsaicin in SMMC-7721 cells was due to apoptosis. In the present study, the results of the apoptosis assay revealed that capsaicin treatment induced apoptosis in a dose-dependent manner in SMMC-7721 cells. Previously, accumulated evidence indicated that caspases, a family of cysteine proteases, play a pivotal role in the apoptotic process; caspase- 3 is an apoptosis executioner and is activated by other activated caspases, including caspas- 8 and $9[27,28]$. Activated caspas- 3 subsequently cleaves certain specific substrates, including poly (ADP-ribosyl) polymerase (PARP) and D4-GDI proteins, which are important for the occurrence of typical biochemical and morphological changes in apoptotic cells [27]. To further confirm that the antiproliferative activity of capsaicin was due to apoptosis, we examined caspase- 3 activity and activation, an event that is commonly used as a hallmark of apoptosis. Our results showed that caspase-3 was activated after capsaicin treatment in SMMC-7721 cells. These results suggest that apoptosis may be a potential general mechanism and provide a mechanistic basis for the antiproliferative as well as anti-neoplastic effects of capsaicin in SMMC-7721 cells.

It is widely accepted that mitochondria plays a pivotal role in apoptotic process [29]. ROS, a group of highly reactive molecules, including singlet oxygen, hydroxyl radicals, superoxide anion, nitric oxide and hydrogen peroxides, have been shown to play a key role in apoptotic cell death [30]. ROS are known to induce the collapse of MMP, therefore trigger a series of mitochondria-associated events including apoptosis [31]. Cytochrome $\mathrm{c}$ is an important regulating factor in the generation of mitochondrial membrane potential. In this study, the level of ROS was significantly increased and the MMP was significantly reduced in capsaicin-treated cells as compared with the control experiment. As was consistent with the previous study [32]. Moreover, when SMMC-7721 cells were pretreated with NAC then treated with capsaicin, our studies revealed that NAC pretreatment not only blocked ROS generation but also offered significant protection against capsaicin-induced mitochondrial membrane potential disruption, release of cytochrome $c$ and apoptosis induction in SMMC-7721 cells. Our results indicated that capsaicin induced apoptosis in SMMC-7721 cells was initiated by the generation of ROS, which was followed by the disruption of the mitochondrial membrane potential and release of cytochrome $\mathrm{c}$ into the cytosol leading to the activation of caspases cascade.

MAPK pathways are a family of serine-threonine protein kinases [33]. C-jun $\mathrm{N}$ terminal kinase (JNK) and p38 MAPK constitute two major subfamilies of MAPK pathways that can participate in apoptosis [34]. JNK and p38 MAPK respond strongly to a variety of stress signals and have been implicated in mediating apoptotic responses [35]. It has been reported that capsaicin induced human gastric cancer cells apoptosis via JNK and p38 MAPK [36]. Based on these previous data, we hypothesized that capsaicin-induced
SMMC-7721 cells apoptosis involves JNK and p38 MAPK pathways. Our data showed that capsaicin induced activation of JNK and p38 MAPK in a dose-dependent manner. Pretreatment of SMMC-7721 cells with JNK and p38 MAPK specific inhibitors (SP600125 or SB203580) almost blocked apoptosis induced by capsaicin. These results suggest that JNK and p38 MAPK were associated for capsaicin-induced apoptosis in SMMC-7721 cells. ROS are the known mediators of intracellular signaling cascades [37]. We also found that the presence of NAC inhibited activation of JNK, and p38 MAPK pathways. These findings suggest that intracellular ROS generation precedes the activation of JNK and p38 MAPK after capsaicin stimulation and ROS may be responsible for capsaicin-mediated activation of JNK and p38 MAPK. Consistent with this finding, a previous study indicated that NAC almost abolished the activation of JNK and p38 MAPK in corneal epithelial cells induced by Advanced Glycation End Products (AGEs) [38].

Taken together, our results demonstrate that capsaicin induced apoptosis in human hepatoma cancer cells is mediated by ROS generation, resulting in the activation of mitochondrial death pathway and the activation of JNK and p38 MAPK pathways, which eventually leaded to apoptosis in SMMC-7721 cells. However, certain molecular links remain to be clarified, such as whether JNK and p38 MAPK pathways are linked to mitochondrial apoptotic pathway, and how that acts on the mitochondrial apoptotic pathway. The specific mechanisms involved require further study. Based on these results, further in vivo and clinical studies are necessary to confirm our findings.

Acknowledgements: We are grateful for the financial support from the Administration of Traditional Chinese Medicine of Zhejiang, China (grant no. 2013ZQ026) and The National Natural Science Foundation of China (grant no. 81202821) for financial support of this study.

\section{References}

[1] FORNER A, LLOVET JM, BRUIX J. Hepatocellular carcinoma. Lancet 2012; 379: 1245-1255. http://dx.doi.org/10.1016/ $\underline{\text { S0140-6736(11)61347-0 }}$

[2] SHERMAN M. Hepatocellular carcinoma: epidemiology, surveillance, and diagnosis. Semin Liver Dis 2010; 30: 3-16. http://dx.doi.org/10.1055/s-0030-1247128

[3] MARRA M, SORDELLI IM, LOMBARDI A, LAMBERTI M,TARANTINO L et al. Molecular targets and oxidative stress biomarkers in hepatocellular carcinoma: an overview. J Transl Med 2011; 9: 171. http://dx.doi.org/10.1186/1479$\underline{5876-9-171}$

[4] JEMAL A, BRAY F, CENTER MM, FERLAY J, WARD E et al. Global cancer statistics. CA Cancer J Clin 2011; 61: 69-90. http://dx.doi.org/10.3322/caac.20107

[5] SIEGEL R, NAISHADHAM D, JEMAL A. Cancer statistics, 2012. CA Cancer J Clin 2012; 62: 10-29. http://dx.doi. org/10.3322/caac.20138 
[6] FERLAY J, SHIN HR, BRAY F, FORMAN D, MATHERS C et al. Estimates of worldwide burden of cancer in 2008: GLOBOCAN 2008. Int J Cancer 2010; 127: 2893-2917. http://dx.doi. org/10.1002/ijc.25516

[7] MALUCCIO M, COVEY A. Recent progress in understanding, diagnosing, and treating hepatocellular carcinoma. CA Cancer J Clin 2012; 62: 394-399. http://dx.doi.org/10.3322/ caac. 21161

[8] LOPEZ PM, VILLANUEVA A, LLOVET JM. Systematic review: evidence-based management of hepatocellular carcinoma--an updated analysis of randomized controlled trials. Aliment Pharmacol Ther 2006; 23: 1535-1547. http://dx.doi. org/10.1111/j.1365-2036.2006.02932.x

[9] TRIPATHI YB, TRIPATHI P, ARJMANDI BH. Nutraceuticals and cancer management. Front Biosci 2005; 10: 1607-1618. http://dx.doi.org/10.2741/1644

[10] HOLZER P. Capsaicin: cellular targets, mechanisms of action, and selectivity for thin sensory neurons. Pharmacol Rev 1991; 43: 143-201.

[11] HARTEL M, DIMOLA FF, SELVAQQI F, MASCETTA G, WENTE MN et al. Vanilloids in pancreatic cancer: potential for chemotherapy and pain management. Gut 2006; 55: 519-528. http://dx.doi.org/10.1136/gut.2005.073205

[12] PRAMANIK KC, BOREDDY SR, SRIVASTAVA SK. Role of mitochondrial electron transport chain complexes in capsaicin mediated oxidative stress leading to apoptosis in pancreatic cancer cells. PLoS One 2011; 6: e20151. http:// dx.doi.org/10.1371/journal.pone.0020151

[13] AMANTINI C, BALLARINI P, CAPRODOSSI S, NABISSI M, MORELLI MB et al. Triggering of transient receptor potential vanilloid type 1 (TRPV1) by capsaicin induces Fas/ CD95-mediated apoptosis of urothelial cancer cells in an ATM-dependent manner. Carcinogenesis 2009; 30: 1320-1329. http://dx.doi.org/10.1093/carcin/bgp138

[14] KIM JY, KIM EH, KIM SU, KWON TK, CHOI KS. Capsaicin sensitizes malignant glioma cells to TRAIL-mediated apoptosis via DR5 upregulation and survivin downregulation. Carcinogenesis 2010; 31: 367-375. http://dx.doi.org/10.1093/ carcin/bgp298

[15] PRAMANIK KC, BOREDDY SR, SRIVASTAVA SK. Role of mitochondrial electron transport chain complexes in capsaicin mediated oxidative stress leading to apoptosis in pancreatic cancer cells. PLoS One 2011; 6: e20151. http:// dx.doi.org/10.1371/journal.pone.0020151

[16] CHO WH, LEE HJ, CHOI YJ, OH JH, KIM HS et al. Capsaicin induces apoptosis in MG63 human osteosarcoma cells via the caspase cascade and the antioxidant enzyme system. Mol Med Rep 2013; 8: 1655-1662. http://dx.doi.org/10.3892/ $\underline{\mathrm{mmr} .2013 .1737}$

[17] LU HF, ChEN YL, YANG JS, YANG YY, LIU JY et al. Antitumor activity of capsaicin on human colon cancer cells in vitro and Colo 205 tumor xenografts in vivo. J Agric Food Chem 2010; 58: 12999-13005. http://dx.doi.org/10.1021/ jf103335w

[18] BROWN KC, WITTE TR, HARDMAN WE, LUO H, CHEN YCet al; Capsaicin displays anti-proliferative activity against human small cell lung cancer in cell culture and nude mice models via the E2F pathway. PLoS One 2010; 5: e10243. http:// dx.doi.org/10.1371/journal.pone.0010243

[19] HUANG SP, CHEN JC, WU CC, CHEN CT, TANG NY et al. Capsaicin-induced apoptosis in human hepatoma HepG2 cells. Anticancer Res 2009; 29: 165-174.

[20] JOUNG EJ, LI MH, LEE HG, SOMPARN N, JUNG YS et al. Capsaicin induces heme oxygenase-1 expression in HepG2 cells via activation of $\mathrm{PI} 3 \mathrm{~K}-\mathrm{Nrf2}$ signaling: $\mathrm{NAD}(\mathrm{P}) \mathrm{H}$ :quinone oxidoreductase as a potential target. Antioxid Redox Signal 2007; 9: 2087-98. http://dx.doi.org/10.1089/ars.2007.1827

[21] SAHU RP, ZHANG R, BATRA S, SHI Y, SRIVASTAVA SK. Benzyl isothiocyanate-mediated generation of reactive oxygen species causes cell cycle arrest and induces apoptosis via activation of MAPK in human pancreatic cancer cells. Carcinogenesis 2009; 30: 1744-1753. http://dx.doi.org/10.1093/ carcin/bgp 157

[22] KROEMER G, GALLUZZI L, BRENNER C. Mitochondrial membrane permeabilization in cell death. Physiol 2007; 87: 99-163. http://dx.doi.org/10.1152/physrev.00013.2006

[23] ZHANG R, HUMPHREYS I, SAHU RP, SHI Y, SRIVASTAVA SK. In vitro and in vivo induction of apoptosis by capsaicin in pancreatic cancer cells is mediated through ROS generation and mitochondrial death pathway. Apoptosis 2008; 13: 1465-78. http://dx.doi.org/10.1007/s10495-008-0278-6

[24] YUAN H, ZHANG X, HUANG X, LU Y, TANG W et al. NADPH oxidase 2-derived reactive oxygen species mediate FFAs-induced dysfunction and apoptosis of beta-cells via JNK, p38 MAPK and p53 pathways. PLoS One 2010; 5: e15726. http://dx.doi.org/10.1371/journal.pone.0015726

[25] SHANMUGAM MK, KANNAIYAN R, SETHI G. Targeting cell signaling and apoptotic pathways by dietary agents: role in the prevention and treatment of cancer. Nutr Cancer 2011; 63: 161-173. http://dx.doi.org/10.1080/01635581.2011.52350 $\underline{2}$

[26] SARKAR FH, LI Y. Using chemopreventive agents to enhance the efficacy of cancer therapy. Cancer Res 2006; 66: 3347-3350. http://dx.doi.org/10.1158/0008-5472.CAN-05-4526

[27] DEGTEREV A, BOYCE M, YUAN J. A decade of caspases. Oncogene 2003; 22: 8543-8567. http://dx.doi.org/10.1038/ sj.onc. 1207107

[28] HAMACHER R, SCHMID RM, SAUR D, SCHNEIDER G. Apoptotic pathways in pancreatic ductal adenocarcinoma. Mol Cancer 2008; 7: 64. http://dx.doi.org/10.1186/1476-4598 $\underline{-7-64}$

[29] GUO W, LIU W, HONG S, LIU H, QIAN C et al. Mitochondria-dependent apoptosis of con A-activated T lymphocytes induced by asiatic acid for preventing murine fulminant hepatitis. PLoS One 2012; 7: e46018. http://dx.doi.org/10.1371/ journal.pone.0046018

[30] OHSAWA I, ISHIKAWA M, TAKAHASHI K, WATANABE M, NISHIMAKI K et al. Hydrogen acts as a therapeutic antioxidant by selectively reducing cytotoxic oxygen radicals. Nat. Med 2007; 13: 688-694. http://dx.doi.org/10.1038/nm1577

[31] PARK MT, KIM MJ, KANG YH, CHOI SY, LEE JH et al. Phytosphingosine in combination with ionizing radiation enhances apoptotic cell death in radiation-resistant cancer cells through ROS-dependent and -independent AIF release. 
Blood 2005; 105: 1724-1733. http://dx.doi.org/10.1182/blood2004-07-2938

[32] LI Q, JIANG C, ZU Y, SONG Z, ZHANG B et al. SFE-CO2 extract from Typhonium giganteum Engl. tubers, induces apoptosis in human hepatoma SMMC-7721 cells involvement of a ROS-mediated mitochondrial pathway. Molecules 2011; 16 : 8228-8842. http://dx.doi.org/10.3390/molecules 16108228

[33] CHEN L, HU W, TAN S, WANG M, MA Z et al. Genomewide identification and analysis of MAPK and MAPKK gene families in Brachypodium distachyon. PLoS One 2012; 7: e46744. http://dx.doi.org/10.1371/journal.pone.0046744

[34] ALIKHANI M, MACLELLAN CM, RAPTIS M, VORA S, TRACKMAN PC et al. Advanced glycation end products induce apoptosis in fibroblasts through activation of ROS, MAP kinases, and the FOXO1 transcription factor. Am J Physiol Cell Physiol 2007; 292: C850-856. http://dx.doi.org/10.1152/ ajpcell.00356.2006
[35] AL-AZAYZIH A, GAO F, GOC A, SOMANATH PR. TGFbeta1 induces apoptosis in invasive prostate cancer and bladder cancer cells via Akt-independent, p38 MAPK and JNK/SAPK-mediated activation of caspases. Biochem Biophys Res Commun 2012; 427: 165-170. http://dx.doi.org/10.1016/j.bbrc.2012.09.035

[36] PARK SY, KIM JY, LEE SM, JUN CH, CHO SB et al. Capsaicin induces apoptosis and modulates MAPK signaling in human gastric cancer cells. Mol Med Rep 2014; 9: 499-502.

[37] RIEMANN A, SCHNEIDER B, IHLING A, NOWAK M, SAUVANT C et al. Acidic environment leads to ROS-induced MAPK signaling in cancer cells. PLoS One 2011; 6: e22445. http://dx.doi.org/10.1371/journal.pone.0022445

[38] SHI L, YU X, YANG H, WU X. Advanced glycation end products induce human corneal epithelial cells apoptosis through generation of reactive oxygen species and activation of JNK and p38 MAPK pathways. PLoS One 2013; 8: e66781. http:// dx.doi.org/10.1371/journal.pone.0066781 